\title{
Corrosion Inhibition of Brass in 0.5 M HNO3 by 3-hydroxy-3- (4-chlorophenyl-1-(4-sulphonato (sodium salt)) Phenyl Triazene (HCST): Adsorption and Thermodynamic Study
}

\author{
Alpana Soni, " Pratibha Sharma, Monika, Rekha Dashora and A.K.Goswami \\ Coordination Laboratory, Department of Chemistry, Mohanlal Sukhadia University, \\ Udaipur, 313001, Rajasthan, India
}

Received September 30, 2015; accepted November 25, 2016

\begin{abstract}
The effect of the concentration and nature of novel 3-hydroxy-3-(4-chlorophenyl-1-(4sulphonato (sodium salt)) phenyl triazene (HCST) on corrosion and dezinfication of $70 / 30$ brass in $0.5 \mathrm{M} \mathrm{HNO} 3$ solution has been investigated by weight loss method. Inhibition efficiency of this corrosion inhibitor was also evaluated at different temperatures ranging from $303 \mathrm{~K}-333 \mathrm{~K}$. It was observed that HCST showed $88.13 \%$ inhibition efficiency at $303 \mathrm{~K}$ up to $0.005 \mathrm{M}$ concentration of inhibitor. Weight loss method has been used to analyze the corrosion behavior of the brass in the absence and presence of different concentrations of inhibitor. The corrosion inhibition efficiency increases with increasing concentration of inhibitor and decreases with rise in temperatures. Activation energy $\left(\mathrm{E}_{\mathrm{a}}\right)$, enthalpy $(\Delta \mathrm{H})$, entropy $(\Delta \mathrm{S})$ and Gibbs free energy $(\Delta G)$ for corrosion process have also been calculated. The adsorption behavior of HCST on brass surface has been found to obey Langmuir adsorption isotherm. Results reveal that hydroxytriazenes can be potential corrosion inhibitors.
\end{abstract}

Keywords: Hydroxytriazene (HCST), corrosion inhibitors, weight loss method, brass, nitric acid.

\section{Introduction}

Dezincification of brass is one of the well-known and common processes by means of which brass loses its valuable physical and mechanical properties leading to structural failure [1]. Corrosion has two specific forms: direct chemical attack and electrochemical attack, and in this both types of corrosion the metal is converted into a metallic compound such as an oxide, hydroxide, or sulfate. Brass has been the most commonly used material for fittings such as stop valves and control valves, shipboard condensers, power plant condensers and petrochemical heat exchangers [2-4]. Due to various industrial applications and economic importance of brass, its protection against corrosion attracts

\footnotetext{
* Corresponding author. E-mail address: alpana.soni94@gmail.com
} 
much attention. One of the most important methods in corrosion protection is the use of inhibitors [5-8].

Many organic compounds, especially those containing polar groups and/or substituted heterocycle including nitrogen, sulphur and oxygen in their structures, have been reported to inhibit the corrosion of copper [9-12]. The inhibiting action of these organic compounds is usually attributed to the formation of donor-acceptor surface complexes between the free or $\pi$ electrons of an inhibitor and the vacant d-orbital of a metal [13-14].

Hydroxytriazenes have been extensively used as spectrophotometric and complexometric reagents for estimation of almost transition metal series. A number of reviews have been published by our laboratory on application of hydroxytriazenes [15-21]. They have also been screened for their biological activities. However, very few studies have been done on their corrosion inhibitive properties. Studies have been done on their behavior for protection of brass in $\mathrm{HNO}_{3}$ medium. It is proven that hydroxytriazenes are potential corrosion inhibitors for brass and copper in ammoniacal medium.

This paper focuses on application of hydroxytriazenes for their corrosion inhibition.

\section{Experimental section \\ Materials and methods}

Synthesis of 3-hydroxy-3-(4-chlorophenyl-1-(4-sulphonato (sodium salt)) phenyl triazene

Step I: Reduction of nitro compounds

In this step 0.05 moles of p-chloronitrobenzene were reduced with $\mathrm{Zn}$ dust in the presence of $\mathrm{NH} 4 \mathrm{Cl}$ in water-alcohol medium using a mechanical stirrer at $40-60{ }^{0} \mathrm{C}$ to obtain phenyl hydroxylamine. The resulting mixture was filtered under suction and the filtrate was kept in fridge to cool.

Step II: Diazotisation of sulphanilic acid

In this step 0.05 mole sulphanilic acid was dissolved in solution of sodium carbonate and cooled to $0-5{ }^{\circ} \mathrm{C}$. Sodium nitrite solution was added to sulphanilic acid solution in acidic medium at $0-5{ }^{\circ} \mathrm{C}$ under constant mechanical stirring to obtain p-sulphonatophenyldiazonium chloride.

\section{Step III: Coupling}

The diazonium compound prepared in step II was added slowly to the phenylhydroxylamine (product of step a) solution under constant stirring at 0-5 ${ }^{0} \mathrm{C}$ and the $\mathrm{pH}$ was maintained among 5-6 by adding solid sodium acetate. The reaction mixture was further stirred for 15 minutes after complete addition of diazonium compound. Sodium chloride was added in sufficient quantity to saturate the solution. The final product obtained was soluble in water, so washing with $\mathrm{H}_{2} \mathrm{O}$ was avoided. The crude compound was recrystallized from double distilled water. Purity of the compounds was checked by recording melting points and other physical characterization methods such as IR, element analysis, 
${ }^{1} \mathrm{H}$ NMR and Mass. It was found that the compounds synthesized are in pure state.

\section{Characterization}

IR spectral analysis and following bands were observed.

IR in $\mathrm{cm}^{-1}$ : 3463 (O-H str.), 3207(N-H str.), 3050 (C-H str. Ar), 2948 (C-H str., $\mathrm{CH}_{3}$ ), 1632 (N=N str.), 1419 (N-Nstr.), 1320 (N-O str), 737(C-Cl str.Ar.). The spectra showed the compound to be in pure state. IR spectra were recorded on FT IR. NMR- $\delta$ (ppm) -12.17 (O-H, s), 7.47-8.11 (multiplet, 8H).

\section{Specimen preparation}

The brass specimens having the chemical composition of $\mathrm{Cu} \sim 70 \%$ and $\mathrm{Zn} \sim 30 \%$ from commercial material were used for experiments by weight loss method with specimens of the dimensions $(2.5 \times 2.5 \times 0.1) \mathrm{cm}$. Each specimen was polished with emery paper, washed with acetone and rinsed by distilled water and dried in an oven and then accurate weight of specimens was determined using an analytical balance of $0.0001 \mathrm{gm}$ accuracy. These specimens were placed in a beaker having $100 \mathrm{~mL}$ solution of $0.5 \mathrm{M} \mathrm{HNO}_{3}$ with and without inhibitor using ' $\mathrm{V}$ ' shape hanging capillary.

\section{Weight loss method}

After initial weighing, the specimens in duplicate were immersed in $100 \mathrm{~mL}$ of acid solution in the presence and absence of different concentrations of the inhibitor at various temperatures ranging 303-333 K. Thermostated water bath was used to maintain temperature; after 24 hours immersion, the specimens were taken out, washed, dried, and the final weight were noted. From initial and final weight of the brass specimen, weight loss in $\mathrm{gm}$, corrosion rate (CR) in gm $\mathrm{cm}^{-2} \mathrm{~h}^{-1}$, inhibition efficacy percentage (IE), and surface coverage $(\theta)$, were determined using equations 1,2 and 3, respectively [22-24].

$$
\mathrm{CR}=\Delta \mathrm{W} / \mathrm{At}
$$

where $\mathrm{CR}$ is the corrosion rate $\left(\mathrm{mgcm}^{-2} \mathrm{~h}^{-1}\right), \Delta \mathrm{W}$ is the weight loss $(\mathrm{g}), \mathrm{A}$ is the surface area, and $t$ is the immersion time in hours.

$$
\begin{gathered}
\mathrm{IE} \%=\left[\left(W_{o^{-}}-W\right) / W_{o}\right] \times 100 \\
\theta=\left[\left(W_{o^{-}}-W\right) / W_{o}\right]
\end{gathered}
$$

where $W_{o}$ and $W$ are the weight-loss in absence and presence of the inhibitor, respectively.

\section{Atomic adsorption spectroscopy}

The spectroscopy has been used to find out the concentration of dissolved copper and zinc in medium solution in which metal / alloy get corroded in the absence and presence of the inhibitor. The concentrations of dissolved copper and zinc in $\mathrm{mg} / \mathrm{L}$ in blank solutions and in solution containing $5 \times 10^{-3}$ moles of the HCST 
after corrosion at $303 \mathrm{~K}$ are shown in Table 1, and IE percentages have been calculated using equation (4) and are also given in Table 1.

$$
\% \mathrm{IE}=\mathrm{C}_{\mathrm{o}}-\mathrm{Ce}_{\mathrm{e}} / \mathrm{C}_{\mathrm{o}}
$$

where $\mathrm{C}_{\mathrm{O}}$ is the concentration of $\mathrm{Cu}$ and $\mathrm{Zn}$ in solution without inhibitor (Blank), and $\mathrm{Ce}_{\mathrm{e}}$ is the concentration of $\mathrm{Cu}$ and $\mathrm{Zn}$ in solution with inhibitor.

Table 1. Dependence of corrosion rates on concentration of HCST at various temperatures.

\begin{tabular}{|c|c|c|c|c|c|c|c|c|c|}
\hline \multirow{2}{*}{ Inhibitors } & \multirow{2}{*}{$\begin{array}{c}\text { Inhibitors } \\
\text { concentration } \\
\text { (moles) }\end{array}$} & \multicolumn{2}{|l|}{$303 \mathrm{~K}$} & \multicolumn{2}{|c|}{$313 \mathrm{~K}$} & \multicolumn{2}{|c|}{$323 \mathrm{~K}$} & \multicolumn{2}{|c|}{$333 \mathrm{~K}$} \\
\hline & & $\mathrm{CR} \times 10^{-4}$ & $\% \mathrm{IE}$ & $\mathrm{CR} \times 10^{-4}$ & $\% \mathrm{IE}$ & $\mathrm{CR} \times 10^{-4}$ & $\% \mathrm{IE}$ & $\mathrm{CR} \times 10^{-4}$ & $\% \mathrm{IE}$ \\
\hline $\begin{array}{l}\text { Without } \\
\text { inhibitor }\end{array}$ & blank & 15.11 & & 26.58 & & 27.64 & & 51.64 & \\
\hline \multirow{3}{*}{ HCST } & $5 \times 10^{-5}$ & 7.46 & 50.59 & 14.10 & 46.92 & 17.08 & 38.18 & 34.10 & 33.95 \\
\hline & $5 \times 10^{-4}$ & 4.40 & 70.84 & 10.81 & 59.31 & 14.59 & 47.29 & 30.74 & 40.45 \\
\hline & $5 \times 10^{-3}$ & 1.79 & 88.13 & 7.5 & 71.78 & 9.24 & 66.57 & 19.24 & 62.74 \\
\hline
\end{tabular}

(a)

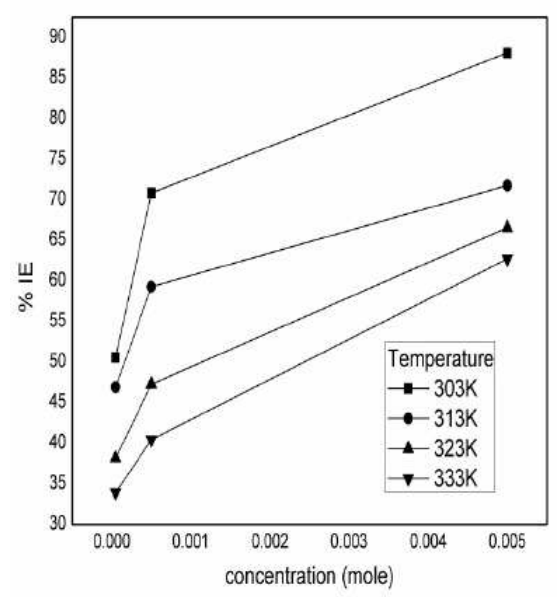

(b)

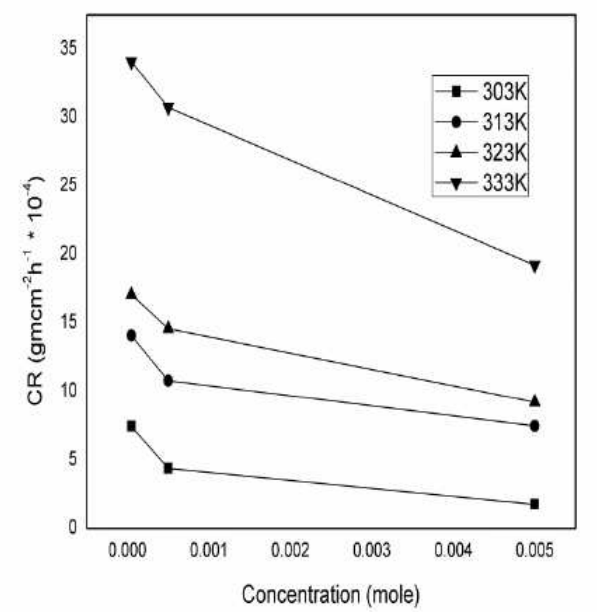

Figure 1. Effect of concentration on (a) IE and (b) corrosion rate.

\section{Results and discussion}

\section{Effect of concentration of HCST on corrosion rate and inhibition efficiency}

The effect on corrosion rate of brass in the absence and presence of various concentrations of the inhibitor (HCST) w a s studied from 303 to $333 \mathrm{~K}$ in 0.5 $\mathrm{M} \mathrm{HNO}_{3}$ medium. The result (Fig. 1) shows that the corrosion rate of brass decreases with increasing the concentration of the inhibitor at all temperatures in $0.5 \mathrm{M} \mathrm{HNO}_{3}$, which shows an increase in adsorptions of the inhibitor on the surface of the brass. The corrosion inhibition efficiency of the inhibitor for brass increases as the concentration of inhibitor increases and decreases with increasing temperature. The IE of HCST is due to the adsorption of its molecules on the brass metal surface. This also depends on the number of 
active sites in the molecule, molecular size and mode of interaction between metal and inhibitor.

\section{Effect of temperature on inhibition efficiency and corrosion rate}

The temperature dependence of IE has been worked out by plotting graphs between temperature and \% inhibition efficiency (IE). The corrosion rate of brass in nitric acid solutions with and without inhibitors (HCST) has also been studied at different temperatures ranging from 303 to $333 \mathrm{~K}$. The resultant observations are shown in Table 1. Fig. 2, is a typical plot of HCST showing that as the temperature increases the inhibition efficiency decreases. The maximum percentage inhibition is $88.13 \%$ at the highest concentration $0.005 \mathrm{M}$ at $303 \mathrm{~K}$.

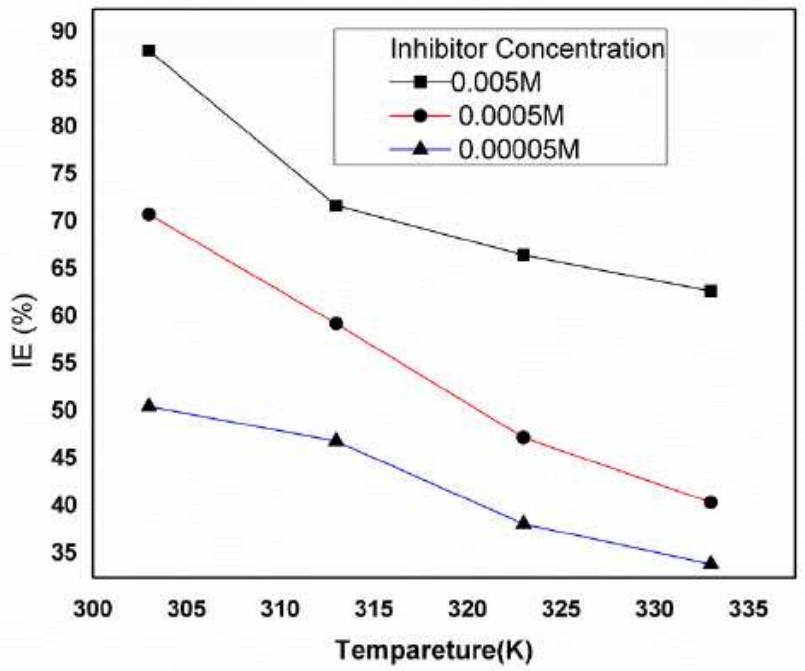

Figure 2. Temperature dependence of IE.

\section{Adsorption isotherm}

Adsorption isotherms are used in determining the mechanism of any organoelectrochemical reaction. Inhibition efficiency $(\%)$ is directly proportional to the surface covered by the adsorbed molecule $(\theta)$. The adsorption isotherm shows the relationship between the surface coverage with the adsorbed species and the concentration of inhibitor in solution. The value of the surface coverage $(\theta)$ at different concentrations of the inhibitors in $0.5 \mathrm{M} \mathrm{HNO}_{3}$ acid solution was fit to adsorption isotherms. HCST inhibitor is found to obey Langmuir adsorption isotherm because the plot of $\mathrm{C} / \theta$ vs. $\mathrm{C}$ is linear. The isotherm is described by equation (5) [25-26].

$$
\mathrm{C} / \theta=1 / \mathrm{K}+\mathrm{C}
$$

where $\mathrm{C}$ is the inhibitor concentration, $\mathrm{K}$ is the adsorption equilibrium constant and $\theta$ is the surface coverage.

\section{Thermodynamic parameters}

\section{Determination of activation energy}

The temperature dependence of the inhibition efficiency and activation energy in the presence and absence of the inhibitor gives the mechanism of the inhibitor adsorption. Inhibition efficiency decreases with increasing temperature, and 
activation energy $\left(\mathrm{E}_{\mathrm{a}}\right)$ increases in the presence of the inhibitor compared to that in the absence of the inhibitor [27]. Thus the activation energy $\left(E_{a}\right)$ for the corrosion process with and without the corrosion inhibitor was evaluated from Arrhenius equation (eq. 6).

The mathematical expression between the corrosion rate $(\mathrm{CR})$ and temperature (T) is generally expressed by the Arrhenius equation [28-29]

$$
\log \mathrm{CR}=\left(-\mathrm{E}_{\mathrm{a}} / 2.303 \mathrm{R}\right)+\log \mathrm{A}
$$

where $\mathrm{CR}$ is the rate of corrosion, $\mathrm{A}$ is the frequency factor, $\mathrm{E}_{\mathrm{a}}$ is the apparent activation energy, $\mathrm{R}$ is the molar gas constant and $\mathrm{T}$ is the absolute temperature.

Fig. 3 curves show the Arrhenius plot in absence and presence of the inhibitor in solutions. Regression coefficients were found to be very close to 1 , which shows a good relationship between $\log \mathrm{CR}$ and $1 / \mathrm{T}$. Straight lines were obtained with slope of $-E_{a} / 2.303 R$. The activation energy $\left(E_{a}\right)$ was calculated from the slope of Arrhenius plot $\left(E_{a}=2.303 \times 8.314 \times\right.$ slope $)$. The activation energy increases as the concentration of the inhibitors (HCST) increases, which indicated physical adsorption on the brass surface. The activation energy of the corrosion process was greater than $20 \mathrm{~kJ} \mathrm{~mol}^{-1}$ [30]. Values of $\mathrm{Ea}$ for the corrosion reaction were calculated and have been given in Table 2 .

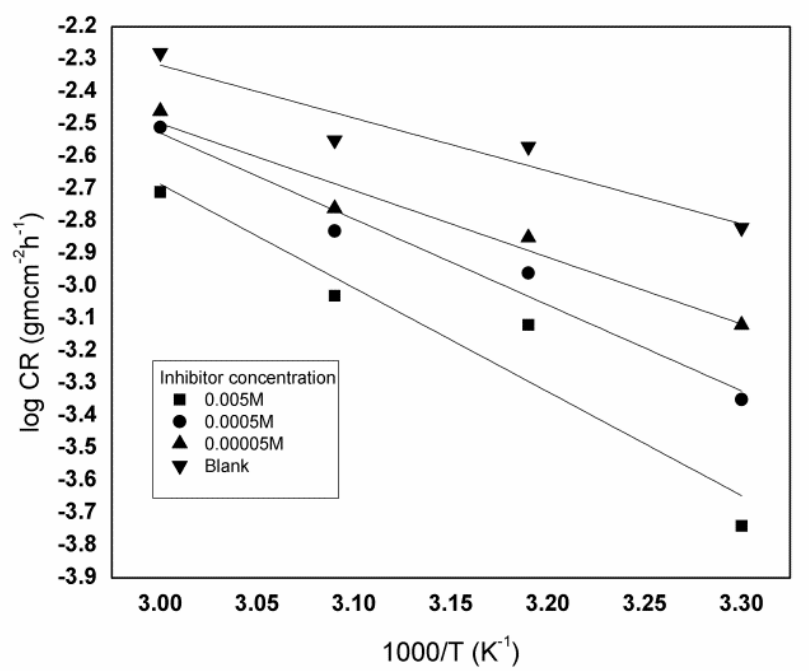

Figure 3. The Arrhenius plot of $\log \mathrm{CR}$ vs.1/T in presence and absence of inhibitor (HCST).

Table 2. Energy of activation in $\mathrm{kJ} / \mathrm{mol}$ at various concentrations.

\begin{tabular}{|c|c|c|}
\hline $\begin{array}{c}\text { Concentration } \\
\text { of inhibitor }\end{array}$ & Slope & $\begin{array}{c}\text { Activation energy } \\
\left(\mathbf{E}_{\mathbf{a}}\right) \mathbf{~ k J} / \mathbf{m o l}\end{array}$ \\
\hline Blank & -1.63 & 31.28 \\
\hline $5 \times 10^{-5}$ & -2.06 & 39.48 \\
\hline $5 \times 10^{-4}$ & -2.65 & 50.75 \\
\hline $5 \times 10^{-3}$ & -3.20 & 61.31 \\
\hline
\end{tabular}

The values of activation energy $\left(\mathrm{E}_{\mathrm{a}}\right)$ for brass corrosion in the presence of HCST in $0.5 \mathrm{M} \mathrm{HNO}_{3}$ are shown in the Table 2. The data show that the activation 
energy $\left(E_{a}\right)$ in the presence of HCST is higher than without the inhibitor. Activation energy $\mathrm{E}_{\mathrm{a}}$ was found to be $31.28 \mathrm{~kJ} / \mathrm{mol}$ for $0.5 \mathrm{M} \mathrm{HNO}_{3}$ and increased to $61.31 \mathrm{~kJ} / \mathrm{mol}$ in the presence $0.005 \mathrm{M}$ concentration of inhibitor at $303 \mathrm{~K}$, showing that the adsorbed organic molecule provided a physical barrier to the charge and mass transfer, leading to reduction in corrosion rate [31].

\section{Determination of enthalpy and entropy}

Other thermodynamic parameters such as enthalpy $(\Delta H)$ and entropy $(\Delta S)$ of activation of the corrosion process may be evaluated from the effect of temperature. The enthalpy $(\Delta \mathrm{H})$ and entropy $(\Delta \mathrm{S})$ of activation of the corrosion process was calculated from equation (7) (Transition state theory) [32]:

$$
\mathrm{CR}=(R T / N h) \exp (\Delta S / R) \exp (-\Delta H / R T)
$$

where CR is the corrosion rate $\left(\mathrm{gmcm}^{-2} \mathrm{~h}^{-1}\right), \mathrm{h}$ is the Plank's constant $\left(6.62 \times 10^{-34}\right.$ J.s), $\mathrm{N}$ is the Avogadro's number $\left(6.022 \times 10^{-23} \mathrm{~mol}^{-1}\right), \mathrm{R}$ is the universal gas constant $\left(8.3144 \mathrm{~J}_{\mathrm{K}}^{-1} \cdot \mathrm{mol}^{-1}\right)$, and $\mathrm{T}$ is the absolute temperature.

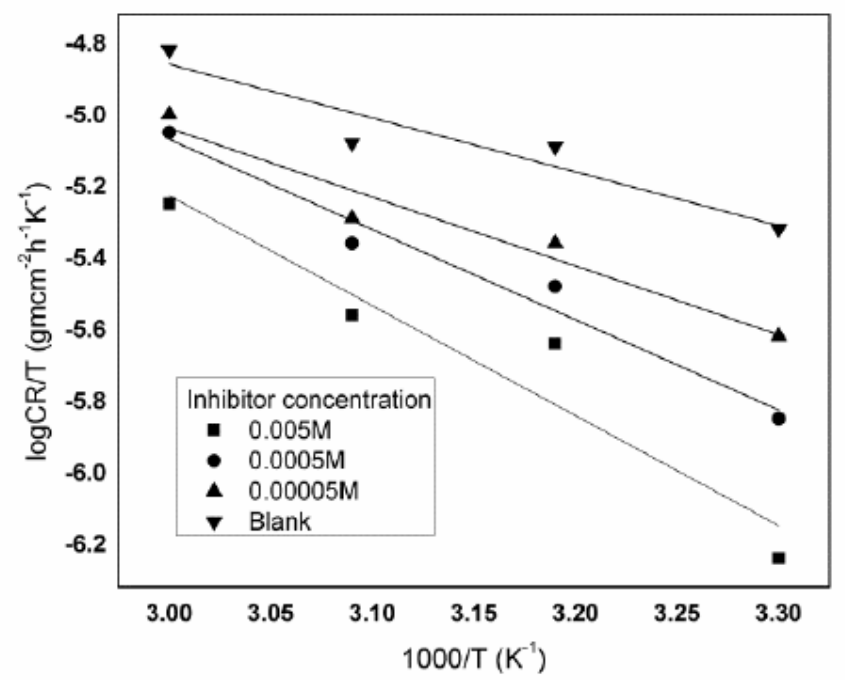

Figure 4. Plot of $\log (\mathrm{CR} / \mathrm{T})$ and $(1000 / \mathrm{T})$ for brass in uninhibited and inhibited $0.5 \mathrm{M}$ $\mathrm{HNO} 3$ solution.

Table 3. Enthalpy and entropy of the reaction with various concentrations of HCST.

\begin{tabular}{|c|c|c|c|}
\hline $\begin{array}{c}\text { Inhibitors' } \\
\text { name }\end{array}$ & $\begin{array}{c}\text { Conc. of } \\
\text { inhibitors }\end{array}$ & $\underset{(\mathbf{k J} / \mathbf{m o l})}{\Delta \mathbf{H}}$ & $\begin{array}{c}\Delta S \\
(\mathbf{J} / \mathbf{m o l ~ K})\end{array}$ \\
\hline \multirow{4}{*}{$\begin{array}{l}\text { 3-hydroxy-3-(4- } \\
\text { chlorophenyl-1-(4- } \\
\text { sulphonato(sodium } \\
\text { salt)phenyltriazene }\end{array}$} & blank & 28.78 & -203.59 \\
\hline & $5 \times 10^{-5}$ & 36.80 & -182.96 \\
\hline & $5 \times 10^{-4}$ & 48.25 & -149.22 \\
\hline & $5 \times 10^{-3}$ & 58.81 & -120.55 \\
\hline
\end{tabular}

A plot of $\log$ CR vs. 1000/T (Fig. 4) is a straight line graph with a slope of ($\Delta \mathrm{H} / 2.303 \mathrm{R})$ and an intercept of $(\log \mathrm{R} / \mathrm{Nh}+\Delta \mathrm{S} / 2.303 \mathrm{R})$ from which the values of $\Delta H(\Delta \mathrm{H}=\mathrm{Slope} \times \mathrm{R})$ and $\Delta \mathrm{S}(\Delta \mathrm{S}=($ Intercept- $\operatorname{lnR} / \mathrm{Nh}) 2.303 \mathrm{R})$ were calculated [33-34]. The results presented in Table 3 show that the enthalpy of activation values is positive, which reflects the endothermic nature of metals or brass dissolution process [35]. Also, the entropies of activation energy were 
positive, indicating that the activation complex represents association steps and that the reaction was spontaneous and feasible [36].

\section{Determination of Gibbs free energy}

The Gibbs free energy of adsorption $(\Delta \mathrm{G})$ characterizes the interaction of adsorption molecules and metal surface, which was calculated by equation (8). The values of $\Delta G$ obtained are presented in Table 4. The negative values of $\Delta \mathrm{G}$ ensure the spontaneity of adsorption process and stability of the adsorbed layer on the brass surface. Generally, the values of $\Delta \mathrm{G}$ around -20 $\mathrm{kJ} / \mathrm{mol}$ or lower are consistent with physisorption, while those around $-40 \mathrm{~kJ} / \mathrm{mol}$ or higher involve chemisorption. As shown in the Table 4, results obtained indicate that the values of $\Delta \mathrm{G}$ are negative. This implies that the HCST is adsorbed on the surface of brass specimen and so gives a very strong inhibition of corrosion. The values of $\Delta \mathrm{G}$ were calculated by the slope of plot of $\mathrm{C} / \theta \mathrm{vs}$. C, Fig. 5, which shows Langmuir adsorption isotherm. Compound HCST, used as an inhibitor, is found to obey Langmuir adsorption isotherm because the plot of $\mathrm{C} / \theta$ vs. $\mathrm{C}$ is linear.

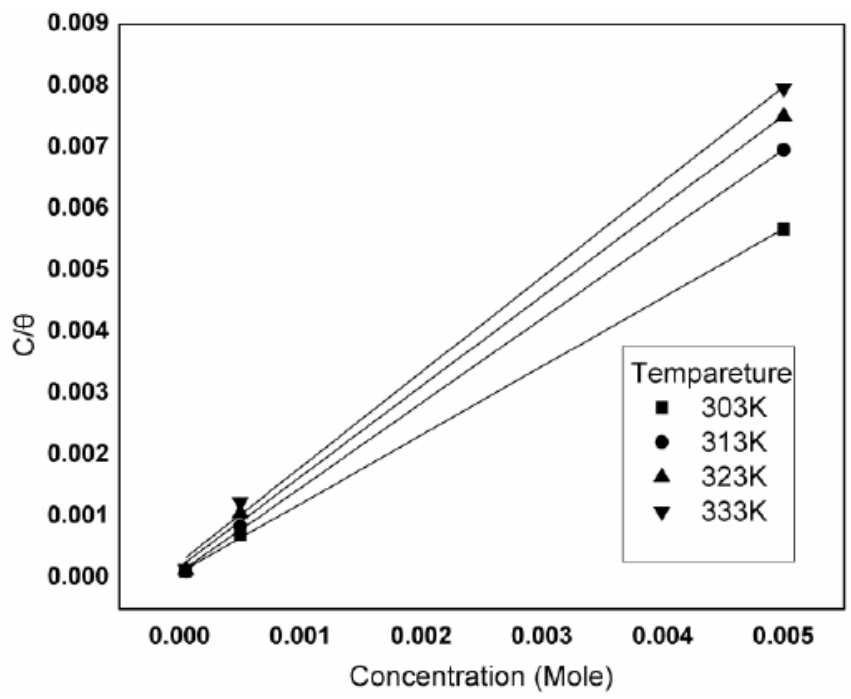

Figure 5. The plot of $(\mathrm{C} / \theta)$ versus $\mathrm{C}$ was linear with the intercept equal to $1 / \mathrm{K}$ for the HCST.

The values for slope and correlation coefficient $\left(\mathrm{R}^{2}\right)$ for the HCST at various temperatures are shown in the Table 4.

$$
\Delta \mathrm{G}=-2.303 \mathrm{RT} \log (55.5 \mathrm{~K})
$$

\section{Atomic adsorption spectroscopy}

These corrosion studies the concentration of corroded and protected $\mathrm{Cu}$ and $\mathrm{Zn}$ were determined by AAS and the results have been shown in Table 5. The results indicate that out of brass sample $\mathrm{Zn}$ is corroded at higher rate than $\mathrm{Cu}$. Further, the inhibitors are more effective to protect corrosion in case of $\mathrm{Zn}$ than in copper. The \% IE by this HCST is $93.29 \%$. We conclude that we can explore this corrosion inhibitor for brass and zinc. 
Table 4. Gibbs free energy at various temperatures of 3-hydroxy-3- (4-chlorophenyl-1(4- sulphonato (sodium salt)) phenyl triazene (HCST).

\begin{tabular}{|c|c|c|c|}
\hline Temperature (K) & Slope & $\Delta \mathbf{G}(\mathbf{k J} / \mathbf{m o l})$ & $\mathbf{R}^{\mathbf{2}}$ \\
\hline 303 & 1.25 & -32.36 & 0.9985 \\
\hline 313 & 1.39 & -33.4 & 0.9986 \\
\hline 323 & 1.44 & -33.33 & 0.9966 \\
\hline 333 & 1.48 & -33.99 & 0.9958 \\
\hline
\end{tabular}

Table 5.Concentration of dissolved $\mathrm{Cu}$ and $\mathrm{Zn}$ in solution having $0.005 \mathrm{M} \mathrm{HCST}$ at 303 $\mathrm{K}$.

\begin{tabular}{|c|c|c|c|c|}
\hline Inhibitors & $\begin{array}{c}\text { Cu } \\
\text { concentration(ppm) }\end{array}$ & \% IE & $\begin{array}{c}\mathbf{Z n} \\
\text { concentration(ppm) }\end{array}$ & \% IE \\
\hline Blank(without inhibitor) & 38.85 & & 399.5 & \\
\hline HCST & 29.6 & 23.80 & 26.65 & 93.32 \\
\hline
\end{tabular}

\section{Conclusions}

The main conclusions are as follows:

1. 3-hydroxy-3-(4-chlorophenyl-1-(4-sulphonato (sodium salt)) phenyl triazene (HCST) shows strong inhibitive action against the corrosion of brass in 0.5 $\mathrm{MHNO} 3$.

2. The inhibition efficiency increases with increasing the inhibitor concentration up to $0.005 \mathrm{M}$ and decreases as the temperature increases.

3. The adsorption of hydroxytriazene on brass obeys Langmuir adsorption isotherm.

4. Hydroxytriazenes are better corrosion inhibitors due to the $\pi$-electrons contribution of benzene ring and presence of more adsorption sites. And these significands are introducing phenyl group and $\mathrm{SO}_{3} \mathrm{H}$ group in compounds.

\section{References}

1. Xavier JR, Nallaiyan R. J Solid State Electrochem. 2012;16:391-402.

2. Warraky A, Shayeb HA, E.M. Sherif EM. Anti-Corros Methods Mater. 2004;51:52-61.

3. Sherif EM, Erasmus RM, Comins JD. J Colloid Interface Sci. 2007;309:470-477.

4. Quartarone G, Moretti G, Bellomi T. Corrosion. 1998;54:606-618.

5. Asan A, Kabasakaloğlu M, Işıklan M, et al. Corros Sci. 2005;47:1534.

6. Sherif EM, Erasmus RM, Comins JD. Corros Sci. 2008;50:3439.

7. Babić-Samardžija K, Hackerman N. J Solid State Electrochem. 2005;9:483.

8. Ranjana RB, Nandi MM, Indian Inst Technol. 2010;17:176-180.

9. Abd El-Maksoud SA. J Electroanal Chem. 2004;565:321-328.

10. Christy AG, Lowe A, Otieno-Alego V, et al. J Appl Electrochem. 2004;34:225-233.

11. Elmorsi MA, Hassanien AM. Corros Sci . 1999;41:2337-2352. 
12. Bouklah M, Benchat N, Hammouti B, et al. Mater Lett. 2006;60:19011905.

13. Bastidas JM, Pinilla P, Cano E, et al. Corros Sci. 2003;45:427-449.

14. Bentiss F, Traisnel M, Lagrene M. J Appl Electrochem. 2001;31:41-48.

15. Kumar S, Goswami AK, Purohit DN. Revs Anal Chem. 2003;22:73-80.

16. Ram G, Chauhan RS, Goswami AK, et al. Revs Anal Chem. 2003;22:255317.

17. Khan S, Dashora R, Goswami AK, et al. Revs Anal Chem. 2004;23:1-74.

18. Dalawat DS, Chauhan RS, Goswami AK. Revs Anal Chem. 2005;24:75102.

19. Singh K, Chauhan RS, Goswami AK. Met Chem. 2005;28:119-148.

20. Upadhyaya M, Chauhan RS, Goswami AK. Met Chem. 2005;28:301-357.

21. Khan R, Mehta A, Dashora R, et al. Revs Anal Chem. 2005;24:149-245.

22. Forty AJ, editor. Physical Metallurgy of Stress Corrosion Fractures. New York: Inter Science; 1959.

23. Uhlig HH, Revie RW. Corrosion and Corrosion Control. New York: Wiley; 1985.

24. Abdallah M, Al-Agez M, Fouda AS. Int J Electrochem Sci. 2009;4:336352.

25. Al-Mhyawi SR. Orient J Chem. 2014;30.

26. Blaedel WJ, Meloche VW. Elementary Quantitative Analysis; Theory and Practice. 2nd edition. New York: Harper \& Row, Publ, Inc. 1963. Pp. 684698.

27. Ebenso EE. Mater Chem Phys. 2003;79:58-70.

28. Rani PD, Selvaraj S. J Phytology. 2010;2:58-64.

29. Gupta SL, Dandia A, Singh P, et al. J Mater Einviron Sci. 2015;6:168-177.

30. Larabi L, Benali O, Mekelleche SM, et al. J Appl Surf Sci. 2006;253:13711378.

31. James AO, Oforka NC, Abiola OK. Bull Electrochem. 2006;22:111-116.

32. Haladky K, Collow L, Dawson J. Br Corros J. 1980;15:20-25.

33. Al-Dokheily ME, Kredy HM, Al-Jabery RN. J Natur Sci Research. 2014;4:17.

34. Behpour M, Ghoreishi SM, Gandomi-Niasar A, et al. J Mater Sci. 2009;44:2444-2453.

35. Quraishi MA, Khan S. J Appl Electrochem. 2006;36:539-544.

36. Umoren AU, Obot IB, Ebenso EE, et al. Port Electrochim Acta. 2008;26:267-282. 